\section{Can we improve referrals for fertility preservation? Evolution of practices after the creation of a fertility network}
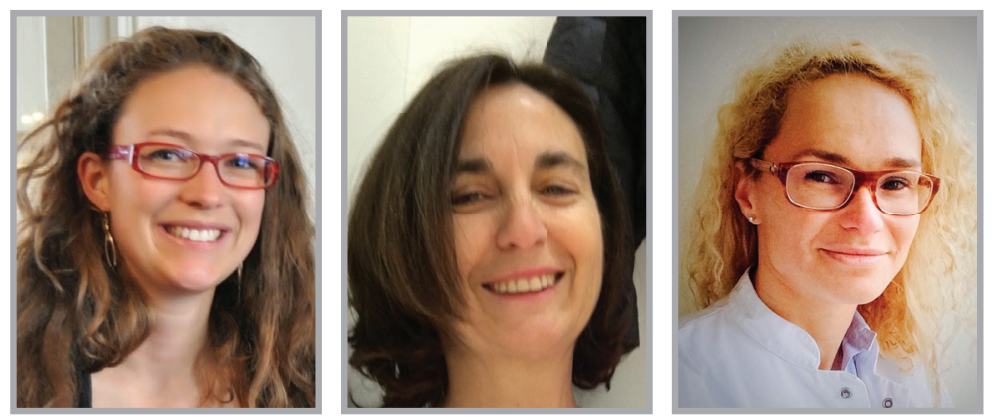

Lise Preaubert ${ }^{* 1,2}$, Michele Pibarot $^{3} \&$ Blandine Courbiere ${ }^{1,2}$

First submitted: 8 June 2016; Accepted for publication: 14 July 2016; Published online: 11 August 2016

Steady advances in cancer care have led to a better consideration of patients' long-term quality of life, with a particular emphasis on fertility-related issues. For patients of reproductive age who have cancer, fertility concerns have a significant psychological impact [1,2], as treatments can impair fertility [3]. Therapeutic protocols involving chemotherapy, radiotherapy or bone marrow transplants are well-established risk factors for subsequent infertility, as they can cause premature ovarian failure and spermatogenesis arrest. These side effects vary according to the type of chemotherapy regimen (molecular compound, dose and combination of treatments), age at the time of treatment and ovarian reserve for women. Furthermore, side effects are subject to major interindividual variations, and recovery is often unpredictable. Moreover, gonadotoxic effects related to chemotherapy might be transmitted to the next generation. International guidelines recommend that patients be informed both of the risk of subsequent treatment-related infertility and of the possibilities for fertility preservation [3-5]. However, oncologists often lack the necessary information and expertise in the fertility field [6-8]. In practice, only few patients are informed of the risks before the start of treatment, and even fewer are offered the possibility to preserve their fertility [9-11]. It also appears that physician practices vary according to their perceptions [12], thus influencing the decisionmaking process. In addition, the literature is scarce concerning the provision of fertility information in France. To improve fertility preservation practices and cancer care, oncofertility networks have been created. In southeast France, a Cancer \& Fertility platform was established in 2012. The Cancer \& Fertility platform provides an up-to-date website [13], a dedicated phone line, communication tools, contact forms for physicians and ready-to-use

\section{KEYWORDS}

- cancer $\bullet$ fertility preservation

- network • oncofertility • support care

“Steady advances in cancer care have led to a better consideration of patients' long-term quality of life, with a particular emphasis on fertility-related issues."

'Department of Obstetrics, Gynecology \& Reproductive Medicine, APHM, La Conception Hospital, Marseille, France ${ }^{2}$ Aix Marseille Univ, Univ Avignon, CNRS, IRD, IMBE UMR7263, Marseille, France

${ }^{3}$ Regional Network of Cancerology ONCOPACA-Corse, hôpitaux Sud, 270, Boulevard Sainte-Marguerite, 13009 Marseille, France

*Author for correspondence: lisepreaubert@free.fr

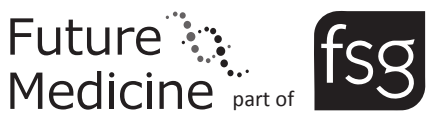


“To provide standardized, updated information and to systematically offer oncofertility counseling to patients of reproductive age, fertility preservation networks should be strongly encouraged." laboratory prescriptions to prepare for fertility consultations. The purpose of this network was to facilitate the contact between oncologists and fertility specialists and to give cancer patients emergency access to a fertility consultation by delivering up-to-date information to both patients and physicians.

Our objectives were to assess the knowledge and practices of physicians concerning fertility preservation in southeast France 3 years after the establishment of a fertility preservation network and to evaluate the Cancer \& Fertility platform. We conducted a prospective survey between September 2014 and June 2015 of physicians working in the southeast region of France, using anonymous questionnaires distributed during multidisciplinary oncology meetings. This study is the second phase of a survey we conducted in 2012, which investigated the knowledge and practices of oncologists involved in oncofertility in the same region [8], prior to the implementation of the Cancer \& Fertility platform. The questionnaire included basic demographics, selfassessment of knowledge of fertility preservation, current practices, in particular information provided to patients, and items evaluating the Cancer \& Fertility platform.

A total of 107 physicians participated in the study (participation rate: 15\%), including $26.2 \%$ oncologists, $20.6 \%$ gynecologists, $10.3 \%$ surgeons, $13.1 \%$ urologists, $6.5 \%$ hematologists, $6.5 \%$ radiotherapists and $16.8 \%$ other specialists. Additionally, $36.4 \%$ of the participants were working in teaching hospitals, $25.2 \%$ in regional hospitals, $21.5 \%$ in a cancer center and $15 \%$ in private hospitals. All physicians self-evaluated their knowledge of fertility preservation (techniques and indications for men, women and children). Their mean scores were $6( \pm 2.6)$ out of 10 for men, $5( \pm 2.5)$ for women and $2.1( \pm 2.4)$ for children. These grades were higher than in 2012, when this self-assessment showed mean scores of $5( \pm 2.8), 3.7( \pm 2.4)$ and $1.3( \pm 2)$ out of ten for men, women and children, respectively. We can, therefore, report an important and positive evolution concerning the information provided to the patient before starting treatment. Indeed, in $2015,81 \%(\mathrm{n}=81)$ of the physicians always or often informed their patients of the risk of subsequent infertility prior to potentially gonadotoxic treatments, compared with $53.8 \%(\mathrm{n}=120)$ in 2012. Furthermore, $75.7 \%$ of the physicians $(\mathrm{n}=75)$ always or often informed their patients of the possibilities of fertility preservation in
2015 before starting treatment, compared with $44.9 \%(n=100)$ in 2012 .

After cancer treatment, $28.4 \%$ of the participants $(n=23)$ always or often checked their patients' fertility parameters (hormonal tests or sperm analysis), compared with $26.1 \%$ in 2012 $(n=54)$. Meanwhile, $71.6 \%$ of them rarely or never checked the fertility parameters after treatment in 2015 ( $n=58)$, compared with $73.9 \%$ in 2012 ( $n=153$ ). Remarkably, $72 \%$ of the physicians had referred patients to an oncofertility consultation in the last 6 months, compared with $46 \%$ in 2012 . Only $10.3 \%$ of the physicians reported difficulties in referring patients to the oncofertility clinic, whereas $30.2 \%$ of them had difficulties in 2012. The main difficulties that were reported were physicians' lack of information about the indications and techniques of fertility preservation $(54.4 \% ; n=6)$, the complexity of integrating fertility preservation into the management of cancer care $(45.4 \% ; n=5)$ and the difficulty obtaining an appointment with an oncofertility specialist in time before starting treatment $(18.2 \% ; n=2)$. Most physicians were aware of the Cancer \& Fertility platform, and the satisfaction rate was high among those who had used it (92\%). The Cancer \& Fertility platform was a source of information for $52.3 \%$ ( $\mathrm{n}=$ 56) of the participants. The number of patients referred to the oncofertility network significantly increased between 2012 and 2015 (355 patients in 2015 compared with 292 patients per year in 2012), especially concerning women and young adults aged 18-25 years, in whom a twofold increase was reported.

This survey showed a global improvement in oncofertility practices among physicians in southeast France 3 years after the implementation of the Cancer \& Fertility platform. This study also provides indicators for the evaluation of practices and information needs and reflects the positive impact of the Cancer \& Fertility platform in our region. Indeed, all practice and information indicators improved, in particular regarding the information provided to patients prior to gonadotoxic treatments, which is paramount. Nonetheless, the fertility preservation techniques concerning women and children remain little known by oncologists, and the referral rates remain low, especially for women and children [10]. Additionally, gender inequalities are observed, with 15.8 versus $2.2 \%$ of men and women, respectively, receiving fertility preservation in France in 2012 [14], mainly due to the complexity and novelty of some of the 
fertility preservation options in women, which include techniques still subject to research, such as ovarian tissue cryopreservation or oocyte in vitro maturation [15,16]. Physicians involved in cancer care should be aware of the fertility preservation options and know how to quickly refer patients to an oncofertility specialist to provide appropriate information to their patients [17]. The provision of information prior to starting treatment is associated with patient satisfaction and improved coping, even if it does not lead to effective fertility preservation [18]. However, it has recently been shown that unmet information needs in young female cancer survivors are frequent (ranging from 43 to 62\%) and are associated with decisional conflict regarding later fertility preservation [19]. To provide standardized, updated information and to systematically offer oncofertility counseling to patients of reproductive age, fertility preservation networks should be strongly encouraged.

\section{Financial \& competing interests disclosure}

The authors have no relevant affiliations or financial involvement with any organization or entity with a financial interest in or financial conflict with the subject matter or materials discussed in the manuscript. This includes employment, consultancies, honoraria, stock ownership or options, expert testimony, grants or patents received or pending, or royalties.

No writing assistance was utilized in the production of this manuscript.

\section{References}

1 Tschudin S, Bitzer J. Psychological aspects of fertility preservation in men and women affected by cancer and other life-threatening diseases. Hum. Reprod. Update 15(5), 587-597 (2009).

2 Deshpande NA, Braun IM, Meyer FL. Impact of fertility preservation counseling and treatment on psychological outcomes among women with cancer: $s$ systematic review. Cancer 121(22), 938-947 (2015).

3 Lee SJ, Schover LR, Partridge AH et al. American Society of Clinical Oncology recommendations on fertility preservation in cancer patients. J. Clin. Oncol. 24(18), 2917-2931 (2006).

4 Jeruss JS, Woodruff TK. Preservation of fertility in patients with cancer. $N$. Engl. J. Med. 360 (9), 902-911 (2009).

5 Peccatori FA, Azim HA, Orecchia R et al. Cancer, pregnancy and fertility: ESMO clinical practice guidelines for diagnosis, treatment and follow-up. Ann. Oncol. 24(Suppl. 6), 160-170 (2013).

6 Adams E, Hill E, Watson E. Fertility preservation in cancer survivors: a national survey of oncologists' current knowledge, practice and attitudes. Br. J. Cancer 108(8), 1602-1615 (2013).

7 Gilbert E, Adams A, Mehanna H, Harrison B, Hartshorne GM. Who should be offered sperm banking for fertility preservation? A survey of UK oncologists and haematologists. Ann. Oncol. 22(5), 1209-1214 (2011).

8

Préaubert L, Poggi P, Pibarot M et al. Fertility preservation among patients with cancer: report of a French regional practical experience. J. Gyn. Obst. Biol. Reprod. 42(3), 246-251 (2013).

9 Anderson RA, Weddell A, Spoudeas HA et al. Do doctors discuss fertility issues before they treat young patients with cancer? Hum. Reprod. Oxf. Engl. 23(10), 2246-2251 (2008).

10 Bastings L, Baysal Ö, Beerendonk CCM, Braat DDM, Nelen WLDM. Referral for fertility preservation counselling in female cancer patients. Hum. Reprod. 29(10), 2228-2237 (2014).

11 Corney RH, Swinglehurst AJ. Young childless women with breast cancer in the UK: a qualitative study of their fertility-related experiences, options, and the information given by health professionals. Psychooncology 23(1), 20-26 (2014).

12 Loren AW, Brazauskas R, Chow EJ et al. Physician perceptions and practice patterns regarding fertility preservation in hematopoietic cell transplant recipients. Bone Marrow Transplant. 48(8), 1091-1097 (2013).

13 La Plateforme régionale Cancer \& Fertilité. www.oncopaca.org/fr/node/1269
14 VICAN 2 cross-sectional study on life two years after cancer, la vie deux ans après un diagnostic de cancer - de l'annonce à l'après cancer, collection études et enquêtes, INCa, Juin 2014.

www.inserm.fr

15 Donnez J, Dolmans MM. Fertility preservation in women. Nat. Rev. Endocrinol. 9(12), 735-749 (2013).

16 Kim SY, Kim SK, Lee JR, Woodruff TK. Toward precision medicine for preserving fertility in cancer patients: existing and emerging fertility preservation options for women. J. Gynecol. Oncol. 27(2), e22 (2016).

17 Lambertini M, Del Mastro L, Pescio MC et al. Cancer and fertility preservation: international recommendations from an expert meeting. BMC Med. 14, 1 (2016).

18 von Wolff M, Giesecke D, Germeyer A et al. Characteristics and attitudes of women in relation to chosen fertility preservation techniques: a prospective, multicenter questionnaire-based study with 144 participants. Eur. J. Obstet. Gynecol. Reprod. Biol. 201, 12-17 (2016).

19 Benedict C, Thom B, N Friedman D et al. Young adult female cancer survivors' unmet information needs and reproductive concerns contribute to decisional conflict regarding posttreatment fertility preservation. Cancer 122(13), 2101-2109 (2016). 